\title{
Effect of an emergency department sepsis protocol on the care of septic patients admitted to the intensive care unit
}

\author{
David D. Sweet, MD; Dharmvir Jaswal, MD; Winnie Fu, MD; Matt Bouchard, MD; \\ Praveena Sivapalan, MD; Jen Rachel, MD; Dean Chittock, MD, MSc
}

\section{ABSTRACT}

Objective: We sought to determine whether the implementation of a sepsis protocol in a Canadian emergency department (ED) improves care for the subset of patients admitted to the intensive care unit (ICU).

Methods: After implementing a sepsis protocol in our ED we used an ICU database and chart review to compare various time-dependent end points and outcomes between a historical control year and the first year after implementation. We reviewed the charts of all patients admitted to the ICU within 24 hours of ED admission with a primary or other diagnosis of sepsis, severe sepsis or septic shock, who met criteria for early goal-directed therapy within the first 6 hours of their ED stay.

Results: We compared 29 patients from the control year with 30 patients from the year after implementation of our sepsis protocol. We found that patients treated during the postintervention year had improvements in time to antibiotics (4.2 v. $1.0 \mathrm{~h}$, difference $=-3.2 \mathrm{~h}, 95 \% \mathrm{Cl}-4.8$ to -2.0$)$, time to central line placement (above the diaphragm) (11.6 v. $3.2 \mathrm{~h}$, difference $=-8.4 \mathrm{~h}, 95 \% \mathrm{Cl}-12.1$ to -4.7$)$, time to arterial line placement (7.5 v. $2.3 \mathrm{~h}$, difference $=-5.2 \mathrm{~h}, 95 \% \mathrm{Cl}-7.4$ to -3.0$)$, and achievement of central venous pressure and central venous oxygen saturation goals ( 11.1 v. $5.1 \mathrm{~h}$, difference $=-6.0 \mathrm{~h}$, $95 \% \mathrm{Cl}-11.03$ to -1.71 , and 13.1 v. $5.5 \mathrm{~h}$, difference $=-7.6 \mathrm{~h}$, $95 \% \mathrm{Cl}-11.97$ to -3.16 , respectively). There were no statistically significant differences in ICU length of stay, hospital length of stay or mortality $(31.0 \%$ v. $20.0 \%$, difference $=-11.0 \%, 95 \% \mathrm{Cl}$ $-33.1 \%$ to $11.1 \%$ ).

Conclusion: Implementation of an ED sepsis protocol improves care for patients with severe sepsis and septic shock.

Keywords: early goal-directed therapy, severe sepsis, septic shock, sepsis protocol, emergency department

\section{RÉSUMÉ}

Objectif : Nous avons voulu vérifier si la mise en œuvre d'un protocole d'asepsie dans un service d'urgence canadien améliore les soins pour un sous-groupe de patients admis à I'unité des soins intensifs (USI).

Méthodes : Après la mise en œuvre du protocole d'asepsie dans notre service d'urgence, nous avons utilisé une base de données de I'USI et procédé à l'examen des dossiers pour comparer différents paramètres des résultats chronologiques entre une année historique témoin et la première année suivant la mise en œuvre du protocole. Nous avons examiné les dossiers de tous les patients admis à I'USI dans les 24 heures suivant leur admission à l'urgence avec un diagnostic principal ou secondaire de sepsis, sepsis grave ou choc septique, et répondant aux critères d'une prise en charge précoce fondée sur l'obtention d'objectifs thérapeutiques prédéterminés dès les six premières heures suivant l'arrivée à l'urgence.

Résultats : Nous avons comparé 29 patients de l'année témoin à 30 patients de l'année suivant l'application de notre protocole d'asepsie. Nous avons constaté que les patients traités durant I'année post-intervention présentaient de meilleurs résultats quant à l'intervalle avant I'antibiothérapie $(4,2$ c. $1,0 \mathrm{~h}$, différence $=-3,2 \mathrm{~h}$, intervalle de confiance [IC] à $95 \%$, de $-4,8$ à $-2,0)$, I'intervalle avant la pose d'un cathéter central (au-dessus du diaphragme) $(11,6$ c. $3,2 \mathrm{~h}$, différence $=-8,4 \mathrm{~h}$, IC à $95 \%$, de $-12,1$ à $-4,7)$, l'intervalle avant la pose d'un cathéter artériel (7,5 c. 2,3 h, différence $=-5,2 \mathrm{~h}$, IC à $95 \%$, de $-7,4$ à $-3,0)$ et l'obtention des objectifs de tension veineuse centrale et de saturation veineuse centrale en oxygène $(11,1$ c. $5,1 \mathrm{~h}$, différence $=-6,0 \mathrm{~h}$, IC à $95 \%$, de $-11,03$ à $-1,71$, et 13,1 c. 5,5 h, différence $=-7,6$ h, IC à $95 \%$, de $-11,97$ à $-3,16$, respectivement). On n'a noté aucune différence statistiquement significative dans la durée du séjour à I'USI, la durée de séjour à I'hôpital ou la mortalité (31,0\% c. $20,0 \%$, différence $=-11,0 \%$, IC à $95 \%$, de $-33,1 \%$ à $11,1 \%)$.

Conclusion : La mise en place d'un protocole d'asepsie à l'urgence améliore les soins aux patients souffrant de sepsis grave et de choc septique.

From the Departments of Emergency Medicine and Critical Care Medicine, Vancouver General Hospital, Vancouver, BC

Submitted Apr. 16, 2009; Revised Dec. 9, 2009; Accepted Dec. 14, 2009

This article has been peer reviewed.

CJEM 2010;12(5):414-20 


\section{INTRODUCTION}

Severe sepsis and septic shock are conditions with a high rate of mortality that are commonly seen in emergency departments (EDs). ${ }^{1}$ Despite extensive research, little progress has been made in improving the survival rates for patients with sepsis. In 2001, Rivers and colleagues $^{2}$ published an article describing early goaldirected therapy (EGDT), which used invasive hemodynamic monitoring and targeted physiologic goals to optimize resuscitation. The study found an absolute reduction in mortality of $16 \%$ when this technique was applied to severely septic patients in the ED. This is the most significant reduction of mortality reported to date in a randomized control trial examining severely septic patients.

The Society of Critical Care Medicine's "Surviving Sepsis Campaign" advocates EGDT in the ED treatment of severe sepsis and septic shock. ${ }^{3}$ In the years since the study by Rivers and colleagues, EGDT has been widely adopted in EDs and several groups have described improved outcomes. ${ }^{3-10}$ There have also been several abstracts published that compare patient outcomes before and after implementation of sepsis protocols. ${ }^{11-13}$ Combined, these studies include 298 patients and describe a mean mortality before EGDT of $44.8 \%$ (standard deviation [SD] 7.8\%), which was reduced to $24.5 \%$ (SD 5.5\%) after implementation of a sepsis protocol. ${ }^{14}$

To date, there have been no full-paper publications on the effectiveness of a sepsis protocol in a Canadian centre. Through a collaboration of emergency medicine, critical care medicine, infectious disease, nursing and pharmacology, we created a sepsis protocol for our ED in 2005. Before the initiation of this protocol, there were no standardized protocols for the management of septic patients. The intensive care unit (ICU) and the ED shared responsibility for such patients, the use of EGDT was sparse and there was variable involvement of emergency physicians. The purpose of this study was to determine the effectiveness of our ED protocol in reducing the time to the achievement of process and physiologic goal-directed end points in septic patients admitted to the ICU.

\section{METHODS}

This was a retrospective cohort study that took place at Vancouver General Hospital, a tertiary level academic centre that has fellowship programs in both emergency and critical care medicine. Vancouver General Hospital has approximately 69000 visits to the ED and 1200 admissions to the ICU per year. The study was approved by our clinical research ethics board.

\section{Protocol development}

Members from the departments of emergency medicine, critical care medicine, infectious disease and pharmacology, as well as senior nursing staff, were invited to join a sepsis working group whose purpose was to develop a local sepsis protocol. A final protocol was developed in April 2005. Following an internal review, a preprinted order set was approved for use in the ED in May 2005, and equipment for the monitoring of central venous pressure (CVP) and invasive arterial monitoring was purchased.

The protocol was similar to that used by Rivers and colleagues, ${ }^{2}$ and was implemented in multiple stages. The first stage involved a triage screening tool to alert physicians to patients who might fit the criteria for EGDT. If, at triage, patients met 2 out of 4 criteria for systemic inflammatory response syndrome (SIRS) and had a suspected infection, a sepsis protocol (Appendix 1, available at www.cjem-online.ca) was placed on the chart and the patient was assigned a Canadian Emergency Department Triage and Acuity Scale ${ }^{15}$ score of 2 . It is important to note that we removed white blood cell count from the SIRS criteria used by Rivers and coauthors, as this would not be available to the triage nurse at the time of initial patient presentation. We also added decreased level of consciousness as a presumed marker of illness severity. Patients who met the above criteria underwent blood tests that included a complete blood count, electrolytes, renal and liver function, and a blood culture. Additionally, a chest radiograph and electrocardiogram were ordered. Finally, venous blood was obtained in an arterial blood gas syringe to facilitate assessment of venous lactate. If the patient was hypotensive, as defined by a systolic blood pressure of less than $90 \mathrm{~mm} \mathrm{Hg}$, an intravenous line was established and an initial 500-mL bolus of normal saline was given. After assessment by the emergency physician, it was determined whether the patient had severe sepsis or septic shock and met the criteria for EGDT, as reflected by a lactate level greater than $4 \mathrm{mmol} / \mathrm{L}$ or continued hypotension despite a $20-30 \mathrm{~mL} / \mathrm{kg}$ bolus of intravenous fluids. If the patient met criteria for EGDT, the emergency physician or the ICU resident would place a central venous catheter (above the diaphragm) and an 
arterial catheter to facilitate resuscitation of the patient according to our EGDT protocol.

An extensive education program on the utility and implementation of the sepsis protocol was provided to all emergency physicians, residents and nursing staff. This included a group lecture conducted in June 2005. Independent sessions were also held for nursing staff exclusively, and this was repeated in November 2006 to incorporate new staff. In addition, every month a lecture was given to incoming residents in the ICU so that they would be aware of the protocol and how to correctly provide EGDT. Finally, a poster with a flow chart of EGDT was placed in the ED as a reference tool.

Our sepsis protocol was introduced into the ED in July 2005. There was no formal data collection during the first 5 months after implementation, as this was considered a grace period during which the staff could become familiar with the use of the protocol. Formal data collection was carried out between Dec. 1, 2005, and Dec. 1, 2006.

\section{Data collection}

To identify study patients we electronically searched a pre-existing ICU patient database that included demographic and clinical parameters on all patients admitted to our ICU. Data entry to the database is performed by ICU nurses, and data are collected concurrently on a daily basis with the review of all notes written about patients by physicians. This includes admission notes, daily progress notes and discharge summaries. The database is maintained, and queries are performed, by a local regional analyst. Using this database, we conducted 2 independent searches. The first search focused on patients admitted approximately 1 year before the implementation of the sepsis protocol (between Jun. 1, 2004, and Jun. 1, 2005) and these patients served as a historical control group. The second search included all patients admitted the year after formal implementation of the sepsis protocol and the previously mentioned grace period, and these patients served as the treatment group. The decision to collect data 1 year before and 1 year after implementation was made for ease of data collection. Inclusion criteria were patients admitted to the ICU within 24 hours of arrival to the ED, who did not require surgery, and who had a primary or secondary diagnosis of sepsis, severe sepsis or septic shock. The database classifies patients as having sepsis, severe sepsis or septic shock if, anywhere in ICU admission notes, daily progress notes or discharge summary, a physician documented the words "sepsis," "severe sepsis" or "septic shock" associated with the patient. Additionally, inferences are made; for example, if a patient was documented as having pneumonia and was on vasopressors, a diagnosis of septic shock would be coded. We excluded patients who went immediately to the operating room from the ED, as we believed resuscitation in the operating room may differ from that in the ED or ICU.

For our primary analysis, we determined which patients in the control and treatment groups qualified for EGDT during the first 6 hours of ED admission, as defined previously, and reviewed all progress notes and nursing notes in their charts to obtain the required data elements. The 3 data abstractors who carried out the chart review were trained by the principle investigator using sample charts. There were no data collection forms, as the data were entered directly into an electronic database. The principle investigator then reviewed all charts and confirmed the information in the electronic database. Regular meetings were then held with the second author, and any discrepancies or ambiguous data were discussed and a final decision made; there were no missing data. There was no blinding of data abstractors and no determination of interrater agreement.

\section{Statistical analyses}

We compared patient characteristics and explanatory variables for differences using SPSS version 16.0. We used $95 \%$ confidence limits around the differences between the groups. Tests of inference were conducted on all outcome variables, using $\chi^{2}$ tests for categorical variables, such as mortality, and $t$ tests for continuous data, such as length of stay. The small number of participants precluded further adjusted analyses.

\section{RESULTS}

In the control year, 40 patients were identified who were transferred to the ICU within 24 hours of their admission to the ED with the diagnosis of sepsis, severe sepsis or septic shock. Of these, 29 were determined to have qualified for EGDT by a lactate level of greater than $4 \mathrm{mmol} / \mathrm{L}$ or by persistent hypotension despite a $20-30 \mathrm{~mL} / \mathrm{kg}$ bolus of normal saline within the first 6 hours of admission. In the treatment year, 60 patients met inclusion criteria, 30 of whom qualified for EGDT. All 30 patients during the treatment year were treated 
using the sepsis protocol and preprinted orders. Table 1 shows the demographics, comorbidities, physiologic variables and sources of infection for the 2 study groups.

Table 2 compares treatments and resuscitation end points between the control and treatment groups. Patients in the treatment year had statistically significant improvements in time to antibiotic administration, time to placement of invasive monitors and time to achievement of hemodynamic end points, with the exception of mean arterial blood pressure. In addition, the treatment group was less likely to require vasopressor support or transfusion of blood products. All patients in both groups received central venous catheters and arterial catheters. Surprisingly, the time to blood culture acquisition, and the amount of volume

\section{Table 1. Characteristics of patients in the control and} treatment groups

\begin{tabular}{|c|c|c|}
\hline \multirow[b]{2}{*}{ Characteristic } & \multicolumn{2}{|c|}{ No. (\%) of patients* } \\
\hline & Control, $n=29$ & Treatment, $n=30$ \\
\hline Mean age (SD), yr & $62.5(17.4)$ & $53.4(17.7)$ \\
\hline \multicolumn{3}{|l|}{ Sex } \\
\hline Male & 19 & 19 \\
\hline Female & 10 & 11 \\
\hline \multicolumn{3}{|l|}{ Comorbidities } \\
\hline Alcohol use & $5(17)$ & $5(16)$ \\
\hline Cardiovascular & $8(28)$ & $4(13)$ \\
\hline Respiratory & $6(21)$ & $5(16)$ \\
\hline Diabetes & $6(21)$ & 2 (7) \\
\hline Hypertension & $6(21)$ & $3(10)$ \\
\hline Liver disease & $14(48)$ & $9(29)$ \\
\hline Neurologic disease & $6(21)$ & $4(13)$ \\
\hline History of cancer & $3(10)$ & $3(10)$ \\
\hline Renal insufficiency & $3(10)$ & $4(13)$ \\
\hline HIV & 1 (3) & $3(10)$ \\
\hline MAP at triage, $\mathrm{mm} \mathrm{Hg}$ & 73.4 & 69.4 \\
\hline \multicolumn{3}{|l|}{$\begin{array}{l}\text { Criteria met for EGDT } \\
\text { because of }\end{array}$} \\
\hline Hypotension & $20(69)$ & $21(70)$ \\
\hline Elevated lactate levels & $14(48)$ & $13(43)$ \\
\hline $\begin{array}{l}\text { Hypotension and } \\
\text { elevated lactate levels }\end{array}$ & $9(31)$ & $7(23)$ \\
\hline \multicolumn{3}{|l|}{ Diagnosis } \\
\hline Pneumonia & $14(48)$ & $18(58)$ \\
\hline Urosepsis & $7(24)$ & $4(13)$ \\
\hline Gastrointestinal infection & $4(13)$ & 2 (6) \\
\hline $\begin{array}{l}\text { Skin and soft tissue } \\
\text { infection }\end{array}$ & $0 \quad(0)$ & $3(10)$ \\
\hline Other & $4(13)$ & $3(10)$ \\
\hline
\end{tabular}

COPD = chronic obstructive pulmonary disease; EGDT = early goal-directed therapy; $\mathrm{MAP}=$ mean arterial pressure; $\mathrm{SD}=$ standard deviation

*Unless otherwise indicated. resuscitation in hours 1, 6 and 24 after admission were similar between the 2 groups. There was a statistically significant reduction in transfusion and steroid use in the treatment group.

Outcome data for the treatment and control groups are displayed in Table 3 . There was no statistically significant difference in mortality rates in the ICU $(16.7 \%$ v. $20.7 \%$, difference $=-4.0 \%, 95 \%$ CI $-23.9 \%$ to $15.9 \%)$ and in hospital $(20.0 \%$ v. $31.0 \%$, difference $=$ $-11.0 \%, 95 \% \mathrm{CI}-33.1 \%$ to $11.1 \%)$. In addition, there was no statistical difference in ICU length of stay, hospital length of stay or days on mechanical ventilation.

\section{DISCUSSION}

We found that the implementation of an ED sepsis protocol reduced the time to key interventions and hastened the achievement of physiologic goals in patients with sepsis, severe sepsis or septic shock who required ICU admission. Patients treated with our sepsis protocol received antibiotics, central venous catheters and arterial catheters sooner than patients in the control group. Additionally, they reached physiologic end points of CVP and central venous oxygen saturation $\left(\mathrm{ScvO}_{2}\right)$ sooner. There was a trend toward more crystalloid volume administered within the first 6 hours during the treatment year, with a median volume given of 6.0 L compared with $4.9 \mathrm{~L}$ in the control year. These findings parallel those of Rivers and colleagues. ${ }^{2}$ Increased volume delivery may have lead to slight improvements in the achievement of hemodynamic variables, but we feel it is more likely that the earlier commencement of hemodynamic monitoring lead to earlier documentation of achievement of CVP and $\mathrm{ScvO}_{2}$ goals.

We found a significant improvement in the time to delivery of antibiotics in our treatment group. As demonstrated by Kumar and colleagues ${ }^{16}$ earlier delivery of antibiotics to patients with septic shock dramatically improves outcomes. As such, we hypothesize that this, along with early attentive care and trends toward greater volumes of crystalloid administered within the first 6 hours, may explain the trends we found toward better clinical outcomes.

Our study demonstrated improved clinical outcomes with decreased vasopressor and steroid use, and trends toward a reduction in ICU and hospital mortality in the treatment group. Additionally, we found decreased APACHE II scores, lactate levels and positive blood cultures in the treatment group. We considered all of these 
variables to be outcomes rather than baseline characteristics, as they are dependent on early resuscitation. It is possible that the differences we found arose from an unexpected difference in the severity of illness; however, the differences can also be explained by the way our data were obtained. For example, the APACHE II score is calculated based on the worst physiologic values recorded during the first 24 hours of admission, and, therefore, patients with superior early management would logically have improved scores. Furthermore, improved early management may have also reduced the requirement for vasopressors and/or steroid supplemen- tation and reduced the number of patients with positive cultures because of early antibiotic delivery.

The implementation of our sepsis protocol may have also resulted in a lower recorded initial lactate level when compared with the control group. As mentioned previously, part of our protocol was to obtain a venous lactate level in an arterial blood gas syringe when the patient was at triage. This would comprise the first lactate level recorded for the patient. In the control year the first lactate level may not have been sent until several hours into the ED visit and potentially after deterioration. Of note, to be included in our study, the sample

\begin{tabular}{|c|c|c|c|}
\hline \multirow[b]{2}{*}{ Variable } & \multicolumn{2}{|c|}{ Median* } & \multirow[b]{2}{*}{ Difference* $(95 \% \mathrm{Cl})$} \\
\hline & Control, $n=29$ & Treatment, $n=30$ & \\
\hline Time from arrival to blood culture taken, $\mathrm{h}$ & 1.64 & 1.28 & $-0.35(-1.06$ to 0.36$)$ \\
\hline Time from arrival to first antibiotic given, $\mathrm{h}$ & 4.22 & 1.01 & $-3.2(-4.77$ to -1.96$)$ \\
\hline Lactate level, mmol/L & 4.7 & 3.2 & $(0.9$ to 15.4$) \neq \quad(0.8$ to 13.8$)$ \\
\hline Culture confirmed positive, no. (\%) & $22(76 \%)$ & $16(53 \%)$ & $23 \% \quad(-1 \%$ to $46 \%)$ \\
\hline APACHE II scoret & 26.86 & 22.00 & $4.89 \quad(1.30$ to 8.49$)$ \\
\hline Time from arrival to ATD CVC placed, $\mathrm{h}$ & 11.60 & 3.20 & $-8.40 \quad(-12.08$ to -4.71$)$ \\
\hline Time from arrival to arterial line placed, $\mathrm{h}$ & 7.52 & 2.32 & $-5.20 \quad(-7.39$ to -3.03$)$ \\
\hline Time from arrival to CVP goal obtained, $\mathrm{h}$ & 11.08 & 5.13 & $-5.95(-11.03$ to -1.71$)$ \\
\hline Time from arrival to MAP goal obtained, $\mathrm{h}$ & 2.79 & 2.17 & $-0.61(-2.08$ to -0.86$)$ \\
\hline Time from arrival to $\mathrm{ScvO}_{2}$ goal obtained, $\mathrm{h}$ & 13.10 & 5.53 & $-7.56 \quad(-11.97$ to -3.16$)$ \\
\hline Resuscitation volume in $1 \mathrm{~h}, \mathrm{~mL}$ & 1098.4 & 1307.9 & $209.5(-326.0$ to 745.0$)$ \\
\hline Resuscitation volume in $6 \mathrm{~h}, \mathrm{~mL}$ & 4931.7 & 5975 & $1043.2(-707.2$ to 2794.0$)$ \\
\hline Resuscitation volume in $24 \mathrm{~h}, \mathrm{~mL}$ & 10410.9 & 10037.3 & $-373.6 \quad(-3489.3$ to 2742.1$)$ \\
\hline Received transfusion, \% & 52 & 31 & $19 \% \quad(6.4 \%$ to $43.2 \%)$ \\
\hline Received steroids, \% & 52 & 23 & $28 \% \quad(4.7 \%$ to $52.0 \%)$ \\
\hline Received APC, \% & 7 & 7 & $0 \% \quad(-13.1 \%$ to $12.6 \%)$ \\
\hline Required vasopressors, \% & 96 & 74 & $22 \% \quad(6 \%$ to $44 \%)$ \\
\hline Received dobutamine, \% & 17 & 19 & $-2 \% \quad(-22.6 \%$ to $17.1 \%)$ \\
\hline Received mechanical ventialtion, \% & 93 & 87 & $6 \% \quad(-8.7 \%$ to $22.5 \%)$ \\
\hline Time from arrival to ICU consult, $\mathrm{h}$ & 4.61 & 2.68 & $-1.93(-4.10$ to 0.24$)$ \\
\hline
\end{tabular}

\begin{tabular}{|c|c|c|c|}
\hline Variable & Control, $n=29$ & Treatment, $n=30$ & Difference* $(95 \% \mathrm{Cl})$ \\
\hline Median ICU LOS, d & 5.0 & 4.1 & 0.14 to $30.00+(0.03$ to 33.1$)$ \\
\hline Median hospital LOS, d & 19.0 & 19.5 & 0.0 to $59.0+(0.0$ to 72.0$)$ \\
\hline $\begin{array}{l}\text { Median time on mechanical } \\
\text { ventilation, } d\end{array}$ & 3.7 & 3.0 & 0.0 to $22.2+$ (0.0 to 22.6 ) \\
\hline Mortality in the ICU, \% & 20.7 & 16.7 & $-4.0(-23.9$ to 15.9$)$ \\
\hline Mortality in hospital, \% & 31.0 & 20.0 & $-11.0(-33.1$ to 11.1$)$ \\
\hline
\end{tabular}


had to be drawn during the first 6 hours of the patient's ED admission.

It is useful to compare our results with those of other locations where sepsis protocols have been implemented in the ED. Jones and colleagues ${ }^{4}$ implemented a sepsis protocol and prospectively recorded data on 79 patients before implementation and 77 patients after implementation. These patients had similar demographic characteristics and lactate levels to the patients in our study, and these investigators found similar results with respect to improvement in time to antibiotics and increased early delivery of fluid. With the implementation of their sepsis protocol, they found an absolute and relative reduction in mortality of $9 \%$ and $33 \%$, respectively. Trzeciak and colleagues ${ }^{3}$ performed a similar study with fewer patients $(n=38)$. They found similar results regarding early fluid delivery, rapidity of antibiotic initiation and a trend toward reduced mortality $(43.8 \% \mathrm{v}$. $18.2 \%, p=0.09)$. Nguyen and coauthors ${ }^{10}$ found similar results in a study examining the completion of 6-hour and 24-hour sepsis bundles. Patients who completed a 6-hour sepsis bundle, which included early invasive monitoring, EGDT and antibiotics, were found to have decreased rates of mortality $(20.8 \%$ v. $39.5 \%, p<0.01)$.

This study has several limitations that should be considered. The greatest limitation of our study is its single-centre design, as it is possible our results may not be generalizable to other centres with a different case mix or organizational structure. Also, in this study we specifically examined patients with sepsis, severe sepsis and septic shock who were admitted to the ICU. As such, if patients were successfully resuscitated in the ED and never required ICU admission, or died in the ED before ICU admission, they would not be captured in our study.

Another limitation is that we had to rely heavily on documentation in medical records to obtain our primary data. We are therefore prone to all the errors and biases that are known to be associated with a retrospective medical record review. These potential problems would have been reduced with a prospective design.

Finally, our design involves the risk of selection bias when comparing an intervention group against a historical control. The characteristics of our 2 groups may differ, as they were treated differently in the ED. Additionally, as the 2 groups were from different periods, there may be other differences in treatment and management beside the sepsis protocol that influenced outcomes. Although we acknowledge these risks, we believe that the patients in the treatment group who came to the ICU may in fact have been a sicker group of patients compared with the control group, as the less sick individuals would have been resuscitated early in the ED and would not have required ICU admission.

\section{CONCLUSION}

Our findings demonstrate that the implementation of an ED sepsis protocol in a Canadian centre can reduce time to delivery of antibiotics and placement of central venous and arterial catheters and can hasten achievement of physiologic variables. Given the ongoing controversies regarding the utility of EGDT, and the call by many for a repeat of the original trial by Rivers and colleagues, we believe that the jury remains out on the effectiveness of ED-driven sepsis protocols and on whether changes in the process of care and early attentive management improve outcomes. Whether value lies in the measurement of $\mathrm{ScrO}_{2}$ and the augmentation of oxygen delivery, or benefits arise simply from attentive care by a specialized team still needs to be determined. Hopefully, the ongoing ProCESS trial by Angus and colleagues ${ }^{17}$ will shed further light on this question.

Competing interests: None declared.

\section{REFERENCES}

1. Nguyen HB, Rivers EP, Abrahamian FM, et al. Severe sepsis and septic shock: review of the literature and emergency department management guidelines. Ann Emerg Med 2006; 48:28-54.

2. Rivers E, Nguyen B, Havstad S, et al. Early goal-directed therapy in the treatment of severe sepsis and septic shock. NEngl J Med 2001;345:1368-77.

3. Trzeciak S, Dellinger RP, Abate NL, et al. Translating research to clinical practice: a 1-year experience with implementing early goal-directed therapy for septic shock in the emergency department. Chest 2006;129:225-32.

4. Jones AE, Foche A, Horton JM, et al. Prospective external validation of the clinical effectiveness of an emergency department-based early goal-directed therapy protocol for severe sepsis and septic shock. Chest 2007;132:425-32.

5. Shapiro NI, Howell MD, Talmor D, et al. Implementation and outcomes of the Multiple Urgent Sepsis Therapies (MUST) protocol. Crit Care Med 2006;34:1025-32.

6. Gao F, Melody T, Daniels DF, et al. The impact of compliance with 6-hour and 24-hour sepsis bundles on hospital mortality in patients with severe sepsis: a prospective observational study. Crit Care 2005;9:R764-70. 
7. Kortgen A, Niederprum P, Bauer M. Implementation of an evidence-based "standard operating procedure" and outcome in septic shock. Crit Care Med 2006;34:943-9.

8. Micek ST, Roubinian N, Heuring T, et al. Before-after study of a standardized hospital order set for the management of septic shock. Crit Care Med 2006;34:2707-13.

9. Sebat F, Johnson D, Musthafa AA, et al. A multidisciplinary community hospital program for early and rapid resuscitation of shock in nontrauma patients. Chest 2005;127:1729-43.

10. Nguyen HB, Corbett SW, Steele R, et al. Implementation of a bundle of quality indicators for the early management of severe sepsis and septic shock is associated with decreased mortality. Crit Care Med 2007;35:1105-12.

11. Rogove J, Pyle K. Collaboration for instituting the surviving sepsis campaign in a community hospital. Crit Care Med 2005;33(12 Suppl):A28.

12. Verceles, A, Schwarcz, RM, Garcha, P, et al. Factors influencing survival in patients with severe sepsis treated with a therapeutic pathway. Chest 2006;130:223S.

13. Stenstrom RJ, Hollohan K, Nebre R. Impact of a sepsis pro- tocol for the management of patients with severe sepsis and septic shock in the emergency department. CJEM 2006;8:S16.

14. Otero RM, Nguyen HB, Huang DT, et al. Early goaldirected therapy in severe sepsis and septic shock revisited: concepts, controversies, and contemporary findings. Chest 2006;130:1579-95.

15. Beveridge R, Clarke B, Janes L, et al. Canadian Emergency Department Triage and Acuity Scale: implementation guidelines. CJEM 1999;1(Suppl3).

16. Kumar A, Roberts D, Wood KE, et al. Duration of hypotension before initiation of effective antimicrobial therapy is the critical determinant of survival in human septic shock. Crit Care Med 2006;34:1589-96.

17. Angus D, Kellum J, Yealy D. Protocolized care for early septic shock (ProCESS). Bethesda (MD): National Library of Medicine; 2009. Available: http://clinicaltrials.gov/ct2/show /NCT00510835. ClinicalTrials.gov identifier: NCT00510835.

Correspondence to: Dr. David Sweet, Department of Critical Care Medicine, Vancouver General Hospital, 855 West 12th Ave., Vancouver BC V5Z 1M9; ddsweet@interchange.ubc.ca

\section{SERVICE INFORMATion}

\section{Subscription and sales}

The Canadian Journal of Emergency Medicine (CJEM) is supplied to active members of the Canadian Association of Emergency Physicians (CAEP) as a benefit of membership. Annual subscriptions are also available. Rates for 2011 (6 issues): Canada (individual), \$225; Canadian institutions, \$495; outside Canada (individual), US\$350; institutions outside of Canada, US\$550. Contact the CAEP office (800 463-1158). Single copies of current year issues available on request; back issues subject to availability. Payment should be made to CAEP in funds drawn on a Canadian or US bank. VISA and MasterCard are accepted.

\section{Change of address}

We require 6-8 weeks' notice to ensure uninterrupted service. Please fax your current mailing label, new address and effective date to 613 523-0190 or email: cjem@caep.ca.

\section{Reprints}

Bulk reprints of CJEM articles are available in minimum quantities of 50 . For information or orders, please contact the reprint coordinator, Janis Murrey, $800663-7336$ or 613731 8610 x2110, fax 613 565-7704, janis.murrey@cma.ca.

\section{Electronic availability}

CJEM is available on the CAEP website (cjem-online.ca).

\section{Indexing}

CJEM is indexed by MEDLINE/PubMed, Embase, CINAHL,
International Pharmaceutical Abstracts (IPA), BIOME/OMNI, Scirus, Cochrane Prehospital and Emergency Health Field, and PubsHub.com

\section{Copyright and permissions}

Copyright for all material is held by CJEM or its licensors unless otherwise indicated. You may reproduce or otherwise use material from this Journal only in accordance with Canadian copyright law and provided that credit is given to the original source. In the case of photocopying or other reprographic copying, please contact the Canadian Copyright Licensing Agency (Access Copyright): 800 893-5777; accesscopyright.ca. For any other use, including republishing, redistribution, storage in a retrieval system or transmission, in any form or by any means, please contact the CJEM Editorial Office, Andrea Schaffeler, Managing Editor, Canadian Journal of Emergency Medicine, 628 Cowan Circle, Pickering ON L1W 3K7; cjem @rogers.com

\section{Instructions for authors}

Published in the January issue of each volume. The most recent version is available online at cjem-online.ca.

\section{Advertising}

Classified ads: Contact Journal Advertising, C7EM, 1867 Alta Vista Dr., Ottawa ON K1G 5W8; 800 663-7336 or 613 731-8610; fax 613 565-7488, advertising@cma.ca. See Classified Advertising section of the Journal for information on rates. Display ads: Contact Journal Advertising (see preceding information). 